\title{
Use of health related quality of life tools in upper gastrointestinal surgery
}

\author{
Muhammad S Sajid*, Mawara Iftikhar, Jasmin Rimpel and Mirza K Baigs \\ Department of Surgery, Worthing Hospital, Worthing. West Sussex. BN11 2DH. UK \\ *Corresponding author: Surgical Research Registrar, Washington Suite, North Wing, Worthing \\ Hospital, West Sussex. BN11 2DH. United Kingdom. Phone: 01903205111 ext. 4030; Mobile: \\ 07891667608; Fax: 01903285 052.; e-mail: surgeon1wrh@hotmail.com
}

\begin{abstract}
SUMMARY
The objective of this article is to review the literature and discuss the various tools used in upper gastrointestinal surgery for the measurement of health related quality of life (HR-QOL) and highlights various outcome variables that affect the HR-QOL among patients of common upper gastrointestinal disorders. The paper reviews HR-QOL articles published in the last 25 years on different upper gastrointestinal curative or palliative procedures. The paper used an HRQOL method, which is a questionnaire, which is utilized to assess the changes in the health status of patients after a surgical intervention. These surveys are of increasingly importance, as health care providers are challenged to justify treatment approaches and rationale for any surgical intervention. These HRQOL tools are very helpful for the evaluation of subjective outcome of common upper gastrointestinal surgical procedures like Gastrointestinal Quality of Life Index (GIQLI) and Quality of life in reflux and dyspepsia (QOLRAD) for Nissen fundoplication, Spitzer's QOL index for gastrectomy, Short Form 36 (SF-36) for achalasia and GIQLI for peptic ulcer disease. The paper concludes that use of validated and reliable health instruments in upper gastrointestinal surgery is directed at measuring the impact in a reproducible and valid fashion. Curative or palliative procedures should be offered to the patients of upper gastrointestinal disorders after the assessment by HR-QOL tools. As the impairment of functions that may occur after different operations vary considerably, an operation-specific assessment of HR-QOL for each type of surgical procedure is becoming an essential principle to follow in a successful healthcare system.
\end{abstract}

[Afr J Health Sci. 2008; 15:14-21]

\section{Introduction}

Based on the modern concepts of health related quality of life (HR-QOL), the principle criteria guiding the patients' acceptance of treatment are most often the patients' subjective feelings i.e. the quality of their lives after surgical, medical or palliative intervention for any upper gastrointestinal disorder [1]. Particularly, surgery offers patients to trade illness related present discomfort and health risk for future gains, in gauging the achievements of surgical treatment. It is important to measure the quality of functional results, which are granted to the patients after any surgical treatment. Another reason which makes the HR-QOL assessment an essential phenomenon is that "surgery is forever" and cannot be undone, unlike medicine, which can be stopped to control the unwanted side effects. Broadening the choice of endpoints beyond traditional, socalled "hard" variables, and including HRQOL in surgical studies have many advantages for both surgeons and patients.

The HR-QOL studies have been developed and performed by both surgeons and non-surgeons with psychometric support [2]. Conduction of research on HR-QOL is helping the surgeons to bridge another divide, opening doors to show more sensitivity, and leading to better communication with their patients and their families. A free, open, polite 
and frank discussion, about HR-QOL gains, as a benefit of surgery, at the time of counselling will go a long way in ensuring that patients' perspectives get their rightful place in decision-making [3]. In this way, both patients and surgeons will benefit from the measurement of HR-QOL. That is why the use of objective criteria (biomedical model) has been replaced by quality of life of the patient (outcomes model) to assess the efficiency of a healthcare system [4]. The objective of this article is to review the literature and discuss the various tools used in upper gastrointestinal surgery for the measurement of HR-QOL. Another purpose of this review is to discuss various outcome variables that affect the HRQOL.

\section{Surgery for the carcinoma of oesophagus}

HR-QOL assessment is an important tool to evaluate the adequate management of patients with oesophageal cancer. It has assumed even more importance in the light of evidence that supports a relationship between patient-rated scores of HR-QOL and improved survival [5, 6]. Dysphagia being the most common symptom of carcinoma of esophagus can be troublesome and can affect all aspects of quality of life [7]. Radical resection (oesophagectomy) remains a formidable surgical procedure for improved survival. The radical resection of the esophagus for carcinoma results in a strong negative impact on HR-QOL. This effect is transient for patients who survive for 2 or more years. After this period their general quality of life is similar to that of healthy individuals of the same age.

This finding should be considered when selecting patients for surgery $[8,9]$. Of the several factors analysed, only tumour recurrence $(\mathrm{P}<0.01)$ and anastomotic stricture $(\mathrm{P}<0.05)$ lower the quality of life significantly [10]. Factors affecting late functional outcome were analysed in two studies and it was shown that patients who had a cervical anastomosis had significantly fewer reflux symptoms $(\mathrm{P}<0.05)$. Dumping syndrome occurred more frequently in younger patients $(\mathrm{P}<0.05)$ and women $(\mathrm{P}<0.01) \quad[11,12]$. Duodenogastroesophageal reflux may eventually be the major cause of morbidity in 10 years after oesophagectomy for carcinoma. Posterior mediastinal reconstruction is a preferred method to achieve the curative resection and to avoid possible local recurrence. However, in the palliative situation, the retrosternal route of reconstruction can also be used, as the functional disadvantages have no negative effect on the quality of life [13]. Similarly, stent placement, as the first choice for inoperable malignant stenosis or oesophageal fistula has improved HR-QOL as much as multiple dilatations by endoscopies $[14,15]$.

It has been shown that patients who were treated by oesophagectomy reported significantly better physical, emotional, cognitive, and global health scores than those in the palliative treatment group [16]. Wong et al have shown that even a palliative oesophagectomy provides enhanced HR-QOL with marked symptomatic benefits and enjoyment of daily living comparable to that observed following curative resection [17]. After curative surgery, most patients have a good appetite and they can take ordinary solid foods. However, about one-third of the patients complain of passage disturbance on swallowing, abdominal pain or diarrhoea after a meal. In these patients management should focus on symptoms that interfere with the patients' HR-QOL. HR-QOL after oesophagectomy, when analysed in detail, shows that the main psychosocial stress is less in the areas of anxiety and depression than in a loss of social activity and impairment of physical capacity.

\section{Surgery for gastric cancer}

Major concerns in HR-QOL after gastrectomy for carcinoma of the stomach are the reservoir function of neo-stomach, absence of dumping, absence or under-performing reflux mechanism and the ability to eat well for the maintenance of weight. Control of these gastrointestinal symptoms is important to minimize or completely abolish the impairment of HR-QOL after partial or complete gastric resection. A variety of instruments and scales have been used to quantify the HR-QOL after gastrectomy. The prime examples include Visick criteria, Karnofsky index, Spitzer's QOL index, Cuschieri's assessment, GIQLI, Goodness of fit index (GFI), and EORTC questionnaires [18].

When restoring the continuity of the gastrointestinal tract after gastrectomy, exclusion of the duodenal passage, although simpler, is responsible for alterations in the 
physiology of gastric emptying due to bypassing the pyloric sphincter. Among various techniques used for bypass, the dysmotility of the Roux limb is seen only in $10-30 \%$ of patients and severe forms are even less frequent. Pouch procedures like the HuntLawrence pouch are used with the Roux-en-Y procedure to augment the neo-stomach's reservoir capacity and to slow down the rapid emptying of food in the small intestine, as both functions are important to avoid dumping syndrome. Food transit through the pouch follows a linear decreasing function and is significantly slower compared to the exponential passage of oesophagojejunostomy, although both patterns remain still accelerated compared to the physiological ranges of gastric emptying [19-21]. The advantages of a pouch become apparent after a considerable period of time and the real assessment of its benefit should be performed after a long follow-up [22, 23]. A randomised controlled trial has shown that a short pouch is more effective than a long pouch in maintaining nutritional maintenance to minimise the symptoms of reflux [24].

Interposition of jejunal loop between the oesophagus and duodenum, although technically more demanding, restores the duodenal continuity, which maximizes absorption and helps in restoring nutrition. Although preservation of the duodenal passage is the more physiological approach to the restoration of the continuity of the digestive tract, surprisingly the expected impact of the duodenal passage on symptoms, nutrition and outcome could not be ascertained by most of the studies, thereby negating the additional operative effort of jejunum interposition. Two randomised controlled trials have compared the outcome after jejunal interposition [25, 26]. After jejunal interposition with pouch formation; statistically proven benefits for pouch reconstruction could not be demonstrated by either study. Perhaps the reason for failure of the physiological superiority of preservation of the duodenal passage not getting translated into clinical benefit lies in the dennervation of the jejunal interposition. Similarly, the pylorus, the pyloric branch of the vagus nerve and the lower oesophageal sphincter are saved in modified surgical procedures ("nearly total gastrectomy" or "function-preserving gastrectomy"), wherever oncologically feasible, in an attempt to improve the motility of the reconstructed digestive tract [27-31]. Clinicians now realize that malnutrition is not an inevitable consequence of total gastrectomy and it can be prevented by an adequate calorie intake, as a close relationship has been observed between dietary intake and postoperative nutritional parameters. In gastrectomized patients a strict nutritional follow-up can ensure an adequate dietary intake [32].

Most authors agree that maintenance of nutritional status and quality of life is similar after partial/subtotal and total gastrectomy, hence total gastrectomy, when clinically indicated, can be safely done without excessive concern about postoperative nutrition [33-35]. A randomised controlled trial has shown that patients who undergo subtotal gastrectomy have a better outcome during the first postoperative year, but patients given a gastric substitute after gastrectomy improve dramatically with the passage of time and have an even better outcome in the long run [36]. Only one prospective randomised controlled trial has compared various techniques of reconstruction after partial gastrectomy, and it favoured Roux en Y as the technique of choice when compared with Billroth I and Billroth II techniques of reconstruction [37].

Patients undergoing total gastrectomy enjoy a good quality of life and most of them return to the preoperative lifestyle in 18 months. The global health status is not negatively influenced by D2 lymphadenectomy and extended gastrectomy [38]. Patients with splenectomy are more affected by treatment than patients without splenectomy [39]. As a palliative measure, gastro-jejunostomy and total gastrectomy performed with $\mathrm{P} 2$ or $\mathrm{P} 3$ peritoneal dissemination has no beneficial effect on the prolongation of survival or improvement of HR-QOL of patients with gastric cancer [40]. Self-expanding metal stents are a safe and efficacious method for palliating malignant gastric outlet obstruction, which has gone to a scale of severity according to gastric outlet obstruction scoring system [41].

\section{Surgery for gastro-oesophageal reflux disease (GORD)}

Many HR-QOL scales have been designed and used for Gastro-oesophageal reflux disease. 
The most commonly used tools include Quality of life in reflux and dyspepsia (QOLRAD), Gastro-oesophageal reflux disease Health related QOL (GERD-HRQOL), Gastrointestinal Quality of life index (GIQLI), Gastrointestinal Symptoms Rating scale (GSRS) and Psychological General WellBeing Index (PGWBI) [42, 43]. It has been consistently shown in many studies that the HR-QOL is improved in patients of GORD after fundoplication (open and laparoscopic) and is close to the level expected in a healthy individual [44-46]. Heartburn score, dysphagia score, regurgitation scores and global QOL scores are superior to medical therapy after laparoscopic fundoplication [47]. Both partial and complete wrapping offer an effective form of therapy for reflux disease with over $85 \%$ patient satisfaction but partial fundoplication has been found to be associated with fewer mechanical side effects [48].

Surgery for GORD is aimed to provide a long-term benefit and eliminate the need for medications. However, reflux symptoms may persist even after surgery due to functional dyspepsia and may spoil the expected outcome in a few patients deranging the quality of life [49]. Apart from medical and surgical interventions many endoscopic techniques have been evolved to control the reflux disease. These techniques include endoscopic suturing, endoscopic radio-frequency treatment of the lower oesophageal sphincter [50], and injection of ethylene vinyl alcohol polymer into the lower oesophageal sphincter. The endoscopic techniques may improve the quality of life but it is a bit too early to compare their outcomes with standard surgery, which remains the gold standard.

\section{Surgery for oesophageal achalasia}

GIQLI, PGWBI and 36-item Short From (SF36) have been frequently used to assess the quality of life of the patients of achalasia after both open and laparoscopic Hellers myotomy $[51,52]$. All available intervention (open, laparoscopic, endoscopic) do not restore normal oesophageal motility, but surgical management of achalasia offers excellent results in most patients with HR-QOL scores matching the controls in the long follow-up of 18 months [53, 54].
Surgery for gastro-duodenal ulcer disease Many researchers have assessed HR-QOL, for both operative and medical management of peptic ulcer disease. At one time, the major share of research was focussed on the effects of various types of vagotomies and their respective outcomes, but the advent of antihistamines agents and proton pump inhibitors have made routine surgery of acid peptic disease almost obsolete. Prior to the development of modern day HR-QOL indices, outcomes of operations for peptic ulcer were measured in terms of Visick grading. Visick grading may be termed as a forerunner of modern day HR-QOL indices for peptic ulcer disease [55]. Surgery is reserved only for complications of peptic ulcer disease like gastric or duodenal perforation, uncontrolled bleeding, stricture formation and suspected malignant transformation. By using gastrointestinal quality of life index (GIQLI), it has been recently shown that peptic perforation does not result in any long-lasting impairment of HR-QOL in survivors and the quality of life improves to near normal in 6 months time after omental patch repair. It was seen that the overall GIQLI score as well as its GI core, GI disease-specific, psychological and physical and social components significantly increase over 3 and 6 months of follow-up, reflecting improvement in HRQOL as perceived by the patients [56].

\section{Implications}

Assessment of HR-QOL has been the missing measurement in healthcare systems all over the world but now it has 'come of age'. HRQOL is being incorporated into the decisions of clinicians and policy-makers in almost every speciality of medicine and surgery. However, HR-QOL measurement in surgery is currently done mainly for the research purposes, and unless it finds a beneficial place in routine clinical practice, it is likely to remain a philosophical exercise. Developments in this field will lead to widespread use of HR-QOL measurements in all surgical disciplines as a part of routine clinical practice. HR-QOL as a prediction of treatment response is another interesting option, even though more work needs to be done in this area. Because the impairments of function that may occur after different operations vary considerably, an operationspecific assessment of HR-QOL for each type 
of surgical procedure is becoming an essential principle to follow in a successful healthcare system. Another important area of growth is incorporation of HR-QOL in both the medical school curriculum and in the continuous professional development programme for clinicians.

\section{References}

1. Troidl H, Kusche J, Vestweber KH, Eypasch E, Koeppen L, Bouillon B. Quality of life: An important endpoint both in surgical practice and research. Journal of Chronic Diseases. 1987; 40: 523-528.

2. Goligher JC. Judging the quality of life after surgical operations. Journal of Chronic Diseases. 1987; 40: 631-3.

3. Glise H, Hallerback B. Quality of Life in gastrointestinal disease-reports from working groups and conclusions. Scandinavian Journal of Gastroenterology. Suppl. 1993; 199: 47-49.

4. Korolija D, Wood-Dauphinee S, Pointner R. Patient-reported outcomes. How important are they? Surgical Endoscopy. 2007; 4:503-507.

5. Watt E, Whyte F. The experience of dysphagia and its effect on the quality of life of patients with oesophageal cancer. European Journal of Cancer Care (Engl). 2003; 12:183-1 93.

6. Blazeby JM, Farndon JR, Donovan J, Alderson D. A prospective longitudinal study examining the quality of life of patients with esophageal carcinoma. Cancer. 2000; 88: $1781-1787$

7. De Boer AG, Genovesi PI, Sprangers MA, Van Sandick JW, Obertop H, Van Lanschot JJ. Quality of life in long-term survivors after curative transhiatal oesophagectomy for oesophageal carcinoma. British Journal of Surgery. 2000; 87: 17161721

8. Zieren HU, Jacobi CA, Zieren J, Muller JM. Quality of life following resection of oesophageal carcinoma. British Journal of Surgery. 1996; 83:1772-1775.
9. McLarty AJ, Deschamps C, Trastek VF, Allen MS, Pairolero PC, Harmsen WS. Esophageal resection for cancer of the esophagus: Long-term function and quality of life. Annals of Thoracic Surgery. 1997; 63:1568-1572.

10. Baba M, Aikou T, Natsugoe S, Kusano C, Shimada K, Kimura S, Fukumot T. Appraisal of ten-year survival following esophagectomy for carcinoma of the esophagus with emphasis on quality of life. World Journal of Surgery. 1997; 21: 282285.

11. Urschel JD, Urschel DM, Miller JD, Bennett WF, Young JE. A metaanalysis of randomized controlled trials of route of reconstruction after esophagectomy for cancer. American Journal of Surgery. 2001; 182:470475.

12. Blazeby JM, Alderson D and Farndon JR. Quality of life in patients with oesophageal cancer. Recent Results in Cancer Research. 2000; 155:193-204.

13. Aoki T, Osaka Y, Takagi Y, Okada R, Shinohara M, Tsuchida A, Sator S and Koyanagi Y. Comparative study of self-expandable metallic stent and bypass surgery for inoperable esophageal cancer. Diseases of the Oesophagus. 2001; 14: 208-211.

14. Blazeby JM, Williams MH, Brookes ST, Alderson D and Farndon JR. Quality of life measurement in patients with oesophageal cancer. Gut. 1995; 37: 505-508.

15. Branicki FJ, Law SY, Fok M, Poon RT, Chu KM and Wong J. Quality of life in patients with cancer of the esophagus and gastric cardia: A case for palliative resection. Archives of Surgery. 1998; 133:316-322.

16. Brunelli C, Mosconi P, Boeri P, Gangeri L, Pizzetti P, Cerrai F, Schicchi A, Apolone G and Tamburini M. Evaluation of quality of life in patients with malignant dysphagia. Tumori. 2000; 86: 134-138.

17. Blazeby JM, Brookes ST and Alderson D. The prognostic value of quality of life scores during treatment for oesophageal cancer. Gut. 2001; 49: 227-230. 
18. Maeda T, Onuoha FN and Munakata T. The effect of postoperative symptoms experince, and personality and psychosocial factors on depression among postgastrectomy patients in Japan. Gastroenterology Nursing. 2006; 29: 437-444.

19. Stier A, Holscher AH, Schwaiger M and Siewert JR. Jejunum pouch after total gastrectomy-clinical and scintigraphic studies of function and quality of life. Zentralblatt fur Chirugie. 1994; 119: 838-844.

20. McAleese P, Calvert H, Ferguson WR and Laired J. Evaluation of "gastric" emptying time in the $\mathrm{J}$ pouch compared with a standard esophagojejunal anastomosis. World Journal of Surgery. 1993; 17: 595599.

21. Thomas H, Heimbucher J, Fuchs KH, Freys SM, DeMeester TR, Peters JH, Bremner $\mathrm{CG}$ and Thiede A. The mode of Roux-en-Y reconstruction affects motility in the efferent limb. Archives of Surgery. 1996; 131: 63-66.

22. Liedman B, Bosaeus I, Hugosson I and Lundell L. Long-term beneficial effects of a gastric reservoir on weight control after total gastrectomy: A study of potential mechanisms. British Journal of Surgery. 1998; 85: 542547.

23. Miyoshi K, Fuchimoto S, Ohsaki T, Sakata T, Ohtsuka S, Takakura N. Long-term effects of jejunal pouch added to Roux-en-Y reconstruction after total gastrectomy. Gastric Cancer. 2001; 4: 156-161.

24. Tanaka T, Kusunoki M, Fujiwara Y, Nakagawa K, Utsunomiya J. Jejunal pouch length influences metabolism after total gastrectomy. Hepatogastroenterology. 1997; 44: 891-896.

25. Nakane Y, Akehira K, Okumura S, Okamura S, Boku T, Okusa $\mathrm{T}$ and Hioki K. Jejunal pouch and interposition reconstruction after total gastrectomy for cancer. Surgery Today. 1997; 27: 696-701.

26. Kobayashi I, Ohwada S, Ohya T, Yokomori T, Lesato H, Morishita Y. Jejunal pouch with nerve preservation and interposition after total gastrectomy. Hepatogastroenterology. 1998; 45: 558-562.

27. Sawai K, Takahashi T, Fujioka T, Minato $\mathrm{M}$, Taniguchi $\mathrm{H}$ and Yamaguchi T. Pylorus-preserving gastrectomy with radical lymph node dissection based on anatomical variations of the infrapyloric artery. American Journal of Surgery.1995; 170: 285-288.

28. Yunfu L, Qinghua Z and Yongjia W. Pylorus and pyloric vagus preserving gastrectomy treating 125 cases of peptic ulcer. Minerva Chirurgica.1998; 53: 889-893.

29. Zhang D, Shimoyama S and Kaminishi M. Feasibility of pyloruspreserving gastrectomy with a wider scope of lymphadenectomy. Archives of Surgery. 1998; 133: 993-997.

30. Ohya $\mathrm{T}$, Ohwada $\mathrm{S}$, Iesato $\mathrm{H}$, Takeyoshi I, Kawashima Y, Ogawa T, Yokomori T and Morishita Y. Jejunal pouch interposition after pyloruspreserving gastrectomy. Journal of Surgical Research. 1999; 86: 177-182.

31. Tomita R, Fujisaki S, Tanjoh K and Fukuzawa M. Operative technique on nearly total gastrectomy reconstructed by interposition of a jejunal $\mathrm{J}$ pouch with preservation of vagal nerve, lower esophageal sphincter, and pyloric sphincter for early gastric cancer. World Journal of Surgery. 2001; 25: 1524-1531.

32. Braga M, Zuliani W, Foppa L, Di Carlo V and Cristallo M. Food intake and nutritional status after total gastrectomy: Results of a nutritional follow-up. British Journal of Surgery. 1988; 75: 477-480.

33. Bozzetti F, Ravera E, Cozzaglio L, Dossena G, Agradi E, Bonfanti G, Koukouras D and Gennari L. Comparison of nutritional status after total or subtotal gastrectomy. Nutrition.1990; 6: 371-375.

34. Buhl K, Lehnert $\mathrm{T}$, Schlag $\mathrm{P}$ and Herfarth C. Reconstruction after gastrectomy and quality of life. World Journal of Surgery. 1995; 19: 558564.

35. Roder JD, Stein HJ, Eckel F, Herschbach P, Henrich G, Bottcher K, Busch R and Siewert JR. Comparison 
of the quality of life after subtotal and total gastrectomy for stomach carcinoma. Deutsche Medizinische Wochenschrift. 1996; 121: 543-549.

36. Svedlund J, Sullivan M, Liedman B and Lundell L. Long term consequences of gastrectomy for patient's quality of life: The impact of reconstructive techniques. American Journal of Gastroenterology. 1999; 94: 438-445.

37. D'Amato A, Montesani C, Cristaldi M, Giovannini C, Pronio A, Ronga G, Santella S, Ventroni G and Ribotta G. Restoration of digestive continuity after subtotal gastrectomy: Comparison of the methods of Billroth I, Billroth II and roux en Y. Randomized prospective study. Annali Italiani de Chirurgia. 1999; 70: 51-56.

38. Diaz De Liano, Oteiza Martinez F, Ciga MA, Aizcorbe M, Cobo F and Trujillo R. Impact of surgical procedure for gastric cancer on quality of life. British Journal of Surgery. 2003; 90: 91-94.

39. Thybusch-Bernhardt A, Schmidt C, Kuchler T, Schmid A, Henne-Bruns D and Kremer B. Quality of life following radical surgical treatment of gastric carcinoma. World Journal of Surgery. 1999; 23: 503-508.

40. Ouchi K, Sugawara T, Ono H, Fujiya T, Kamiyama Y, Kakugawa Y, Mikuni $\mathrm{J}$ and Yamanami $\mathrm{H}$. Therapeutic significance of palliative operations for gastric cancer for survival and quality of life. Journal of Surgery Oncology. 1998; 69: 41-44.

41. Adler DG and Baron TH. Endoscopic palliation of malignant gastric outlet obstruction using self-expanding metal stents: Experience in 36 patients. American Journal of Gastroenterology. 2002; 97: 72-78.

42. Kamloz T, Granderath FA and Pointner R. The outcome of laparocopic antireflux surgery in relation to patients' subjective degree of compliance with former antireflux medication. Surgical Laparoscopy Endoscopy and Percutaneous Techniques. 2003; 13: 155-160.

43. Olberg P, Johannessen R, Johnsen G, Myrvold HE, Bjerkeset T, Fjosne U and Petersen H. Long term outcome of surgically and medically treated patients with gastroesophageal reflux disease: a matched pair follow up study. Scandinavian Journal of Gastroenterology. 2005; 40: 264-274.

44. Kamolz T, Bammer T, Wykypiel H Jr, Pasiut $\mathrm{M}$ and Pointner R. Quality of life and surgical outcome after laparoscopic Nissen and Toupet fundoplication: One-year follow-up. Endoscopy. 2000; 32: 363-368.

45. Barrat C, Capelluto E, Catheline JM and Champault GG. Quality of life 2 years after laparoscopic total fundoplication: A prospective study. Surgical Laparoscopy and Endoscopy and Percutaneous Techniques. 2001; 11: $347-350$.

46. Granderath FA, Kamolz T, Schweiger UM, Passiut M, Wykypiel H Jr, and Pointner R. Quality of life and symptomatic outcome three to five years after laparoscopic Toupet fundoplication in gastroesophageal reflux disease patients with impaired esophageal motility. American Journal of Surgery. 2002; 183: 110116.

47. Fernando HC, Schauer PR, Rosenblatt M, Wald A, Buenaventura P, Ikramuddin S, Lekutich D. Quality of life after antireflux surgery compared with nonoperative management for severe gastroesophageal reflux disease. Journal of American College of Surgeons. 2002; 194: 23-27.

48. Zugel N, Jung C, Bruer C, Sommer P, Breitschaft K. A comparison of laparoscopic Toupet versus Nissen fundoplication in gastroesophageal reflux disease. Langenbecks Archives of Surgery. 2002; 386: 494-498.

49. Slim K, Bousquet J, Kwiatkowski F, Lescure G, Pezet D, Chipponi J. Quality of life before and after laparoscopic fundoplication. American Journal of Surgery. 2000; 180: 41-45.

50. Hubbard N, Velanovich V. Endoscopic endoluminal radio frequency ablation of Barrett's esophagus in patients with fundoplications. Surgical Endoscopy. 2007; 21: 625-628. 
51. Mattioli S, Ruffato A, Di Simone MP, Lugaresi ML, D'Ovidio F. Comparison between subjective and objective assessement of the long-term results after the Heller-Dor operation in patients affected by oesophageal achalasia. Digestive Liver Disease. 2006; 38: 544-551.

52. Ben-Meir A, Urbach DR, Khajanchee YS, Hansen PD, Swanstrom LL. Quality of life before And after laparoscopic Heller myotomy for achalasia. American Journal of Surgery. 2001; 181: 471-474.

53. Luketich JD, Fernando HC, Christie NA, Buenaventura PO, Keenan RJ, Ikramuddin S, Schauer PR. Outcomes after minimally invasive esophagomyotomy. Annals of Thoracic Surgery. 2001; 72: 19091912.

54. Decker G, Borie F, Bouamrirene D, Veyrac M, Guilan F, Fingerhurt A, Millat B. Gastrointestinal quality of life before and after laparoscopic heller myotomy with partial posterior fundoplication. Annals of Surgery. 2002; 236: 750-758.

55. Visick AH. A study of failures after gastrectomy. Annals of the Royal College of Surgeons of England. 1948; 3: 266-284.

56. Joneja JS, Sharma DB, Sharma D, Raina VK. Quality of Life after peptic perforation. Journal of the Association of Physicians of India. 2004; 52: $207-$ 209. 